\title{
Molecular and phylogenetic studies of Colletotrichum truncatum associated with soybean anthracnose in India
}

\author{
Marmat $\mathrm{N}^{1,2}$, Ansari $\mathrm{MM}^{1}$, Chand $\mathrm{S}^{2}$ and Ratnaparkhe $\mathrm{MB}^{1^{*}}$ \\ ${ }^{1}$ Indian Institute of Soybean Research, Indian Council of Agricultural Research, Indore (M.P.), India \\ ${ }^{2}$ School of Life Sciences, Devi Ahilya University, Indore (M.P.), India
}

Marmat N, Ansari MM, Chand S, Ratnaparkhe MB 2017 - Molecular and phylogenetic studies of Colletotrichum truncatum associated with soybean anthracnose in India. Plant Pathology \& Quarantine 7(2), 146-152, Doi 10.5943/ppq/7/2/7

\begin{abstract}
Colletotrichum species are destructive pathogens of soybean causing anthracnose disease in preand post-harvest stages. Colletotrichum truncatum, which is associated with soybean anthracnose, was isolated from four geographical locations of India. Isolates were identified and grouped on the basis of rDNA internal transcribed spacer (ITS1 and ITS2) sequences. Multiple sequence alignment showed that one isolate had nucleotide variation at two positions, indicating genetic variability within $C$. truncatum. A maximum likelihood phylogenetic tree constructed for all the isolates indicated high sequence similarity of $C$. truncatum isolates. This study identified new $C$. truncatum isolate associated with soybean anthracnose which is different from the previously reported $C$. truncatum isolates.
\end{abstract}

Key words - genetic variability - maximum-likelihood - phylogenetic - ribosomal ITS region sequencing

\section{Introduction}

Colleotrichum truncatum causing anthracnose, is the most important seed-borne fungal pathogen of soybean (Sinclair \& Backman 1989). The pathogen produces a significant reduction of seed germination, seed quality and yield loss in warm and humid subtropics. In India, anthracnose is also considered the most serious soybean disease (Khare \& Chacko 1983), and up to 100\% yield losses have been reported (Sinclair \& Backman 1989, Ploper \& Backman 1992, Manandhar \& Hartman 1999). Disease severity disease and yield loss can vary from location to location. Stability of morphological traits and the existence of intermediate forms due to environmental influence are not always adequate for reliable differentiation among Colletotrichum species, hence making it difficult to classify species for taxonomical studies. Primarily, morphological classification of Colletotrichum species is supported by conidial and appressorial size and shape. Molecular techniques provide alternative methods in solving the problems of species delimitations (MacLean et al. 1993, Jayawardena et al. 2016, Diao et al. 2017). Evolutionary divergence within Colletotrichum species can be detected by using highly conserved rDNA genes that include 18S, 5.8S and $28 \mathrm{~S}$ segments that code for rRNA. These genes are separated by two less conserved regions, the internal transcribed spacers 1 and 2 (ITS1 and ITS2). The sequence analysis of ITS 
regions has proved useful in studying phylogenetic relationships and is also accepted as a universal DNA barcode marker for fungi including Colletotrichum species. The ITS1 and ITS2 spacers show a high rate of evolution and have proved to be robust evolutionary markers for determining intraand inter- specific relationships. Shi et al. (2008) used ITS universal primer pair ITS5/ITS4 to characterize Colletotrichum acutatum and C. gloeosporioides isolates from flowering dogwood (Cornus florida). Similarily, Katoch et al. (2016) carried out a metageographic population analysis of Colletotrichum truncatum associated with chili fruit rot and other hosts using ITS region nucleotide sequences. ITS fungal primers were used for detection of seed borne infection of soybean in Northern Karnataka (Sajeesh et al. 2014). A similar approach has been used to evaluate systematics of Colletotrichum spp. (Bailey et al. 1996, Sherrif et al. 1994, Sreenivasaprasad et al. 1996), and relatedness of anthracnose isolates causing diseases on crops (Johnston \& Jones 1997, Ford et al. 2004). This study evaluates the genetic variability using rDNA-ITS sequences of Colletotrichum truncatum isolates from soybean cultivated in different geographic regions of India.

Table 1 Geographic origin of Colletotrichum truncatum isolates used in this study.

\begin{tabular}{llll}
\hline Isolate ID & \multicolumn{1}{c}{$\begin{array}{c}\text { GenBank } \\
\text { Accession No. }\end{array}$} & \multicolumn{1}{c}{ Host } & \multicolumn{1}{c}{ Geographical regions } \\
\hline CoT1 & KY287672 & Glycine max & Amravati, Maharashtra (Western India) \\
CoT2 & KY287673 & Glycine max & Palampur, H.P. (Northern India) \\
CoT3 & KY287674 & Glycine max & Dhar, M.P, (Central India) \\
CoT4 & KY287675 & Glycine max & Indore, M.P, (Central India) \\
CoT5 & KY287676 & Glycine max & Jabalpur, M.P, (Central India) \\
CoT6 & KY287677 & Glycine max & Umiam, Meghalaya (North-East region of India) \\
\hline
\end{tabular}

\section{Materials \& Methods}

\section{Collection and isolation of Colletotrichum species}

Six soybean isolates of Colletotrichum species were collected from different regions of India (Table 1). The isolates were cultured on potato dextrose agar (PDA) medium for 10-14 days. For harvesting of mycelia, a small piece of fungal colony was transferred to potato dextrose broth containing streptomycin and incubated for two weeks at room temperature in aseptic conditions.

\section{Genomic DNA extraction}

The freshly grown mycelia in potato dextrose broth was filtered on Watman filter paper and rinsed with sterile water. The harvested mycelium, approximately $1 \mathrm{~g}$, was crushed to powder in liquid nitrogen using a sterile mortar and pestle. The DNA extraction was done by modified CTAB method (Schafer \& Wostmeyer 1992) comprising of 2\% CTAB, $100 \mathrm{mM}$ Tris-HCl (pH 8.0), 20 mM EDTA, $1.4 \mathrm{M} \mathrm{NaCl}$ and 1\% 2-mercaptoethanol extraction buffer. The quality of extracted DNA was determined on $0.8 \%$ agarose gel.

\section{Polymerase chain reaction}

ITS primers (ITS5/ITS4) were used to amplify the internal transcribed regions 1 and 2 of fungal isolates (White et al. 1990). A reaction mixture of $25 \mu 1$ total volume was prepared containing 10X PCR buffer with $25 \mathrm{mM} \mathrm{MgCl}_{2}, 2 \mathrm{mM}$ dNTPs mixture, $0.01 \mu$ mol of each primer, 5 units of Taq polymerase and $25 \mathrm{ng}$ DNA template. Amplification was performed in a thermocycler programmed for initial step of denaturation at $94^{\circ} \mathrm{C}$ for 4 mins, followed by 35 cycles of denaturation at $94^{\circ} \mathrm{C}$ for $30 \mathrm{secs}$, annealing at $52^{\circ} \mathrm{C}$ for ITS primers for $30 \mathrm{sec}$ and an extension 
at $72^{\circ} \mathrm{C}$ for $30 \mathrm{sec}$. After 35 cycles, an extra elongation at $72^{\circ} \mathrm{C}$ for 5 mins was done and a final hold at $4^{\circ} \mathrm{C}$. The PCR products were analyzed in $0.8 \%$ agarose in $10 \mathrm{X}$ TAE buffer and size of amplified products were determined.

Table 2 Geographical origin, host information and accession number of referral Colletotrichum ITS sequences used for genetic analysis

\begin{tabular}{clcll}
\hline Isolate & GenBank ID & $\begin{array}{c}\text { Length ITS } \\
\text { (bp) }\end{array}$ & Host & Country \\
\hline & GU227880 & 522 & Capsicum annuum & India \\
& GU227866 & 522 & Glycine max & USA \\
& AF451899 & 606 & Lens culinaris & Australia \\
& KJ677256 & 552 & Jatropha curcas & Mexico \\
Colletotrichum truncatum & JN390854 & 584 & Polianthes tuberosa & India \\
& KX197395 & 604 & Hylocereus sp. & Taiwan \\
& KX197396 & 604 & Hylocereus sp. & Taiwan \\
& KX197397 & 604 & Hylocereus undatus & Taiwan \\
& KJ425579 & 552 & Amorphophallus muelleri & China \\
& JX487153 & 554 & Peucedanum praeruptorum & China \\
\hline
\end{tabular}

\section{Sequencing and phylogenetic analysis}

The purified PCR products of 5.8S/ITS region were sequenced twice using forward and reverse primers. Sequences were deposited in GenBank and compared against those sequence already found in the databases using the Basic Local Alignment Search Tool (BLAST) of NCBI (Table 2). ITS 1 and ITS 2 including 5.8S sequences were aligned using multiple sequence alignment program CLUSTALW. Phylogenetic analyses were conducted in MEGA 6.0. by maximum likelihood (ML) method. The evolutionary distances were computed using the maximum composite likelihood method and all positions containing gaps and missing data were eliminated from the data sets. Clade stability was assessed in bootstrap analyses with 1000 replicates.

\section{Demographic modelling}

To determine whether a model of the population expansion was applicable to isolates we performed the neutrality test of Tajima's D statistics to estimate deviation from selective neutrality (Ramdeen et al. 2012). All the parameters were tested against the expected values under the hypothesis of a recent population expansion based on 1000 bootstrap replicates. Tajima's D was calculated to test for neutrality (Tajima 1989). Neutrality test was used as an indication of recent population expansion when the null hypothesis of neutrality was rejected due to significant negative values where Tajima's $\mathrm{D}$ statistic was significant at $\mathrm{P} \leq 0.05$.

\section{Results}

Six pathogenic Colletotrichum strains (CoT1 to CoT6) were isolated from typical anthracnose lesions found on stems of soybean from four different locations of India (Table 1). When grown on PDA, the colour and appearance of the Colletotrichum isolates varied from cottony white to dark grey (Fig. 1). 


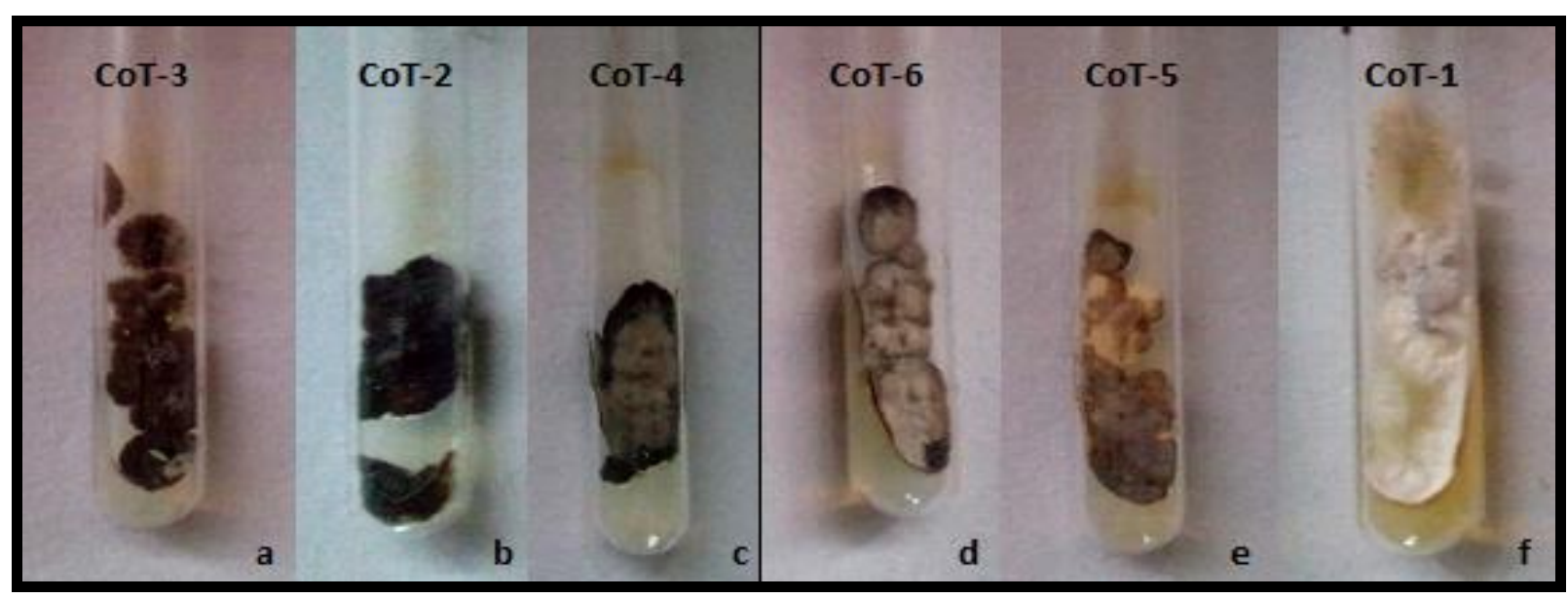

Fig 1 - Colony characters of Colletotrichum truncatum on potato dextrose agar medium. Isolates collected from different regions of India (a) Dhar, Madhya Pradesh, (b) Palampur, Himachal Pradesh, (c) Indore, Madhya Pradesh, (d) Umiam, Meghalaya, (e) Jabalpur, Madhya Pradesh, (f) Amravati, Maharashtra.

\section{Sequence analysis of the ribosomal DNA spacer sequence (ITS)}

PCR amplification and sequencing of 5.8S/ITS regions of the six isolates was conducted for genetic variability studies. The total size of the ITS 1 and ITS 2 regions, including the 5.8S rDNA region of the isolates studied was 580 base pairs. Multiple sequence alignment of all the six isolates along with the reference sequences of $C$. truncatum was carried out to identify the variations at nucleotide level. Multiple sequence alignment indicated that five Indian isolates (CoT1, CoT2, CoT3, CoT4, and CoT6 have $100 \%$ similarity with the 5.8S/ITS region of other $C$. truncatum isolates from GenBank. Isolate CoT5 differed in nucleotide A at position 74 and nucleotide $\mathrm{G}$ at position 97 (Fig. 2).

\begin{tabular}{|c|c|}
\hline & $\begin{array}{l}\text { 74th Position } \\
\overbrace{}^{8}\end{array}$ \\
\hline $\begin{array}{l}\text { KY287674 } \\
\text { KY287677 }\end{array}$ & 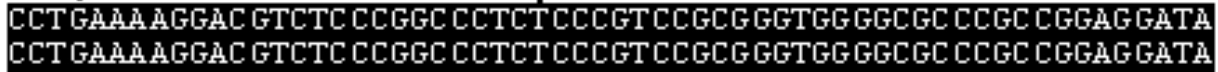 \\
\hline $\mathrm{KY} 827675$ & CCTGAMAAGGAC GTCTC CCGGC CCTCTCCCGTCCGCGGGTGG GGCGC CCGC CGGAGGATA \\
\hline $\begin{array}{l}\text { KY2 } 287676 \\
\text { GU227880 }\end{array}$ & 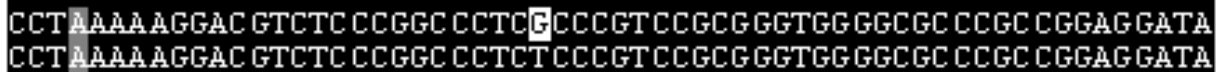 \\
\hline $\begin{array}{l}\text { JN390854 } \\
\text { AF } 451899\end{array}$ & $\begin{array}{l}\text { CCTGAAAAGGAC GTCTC CCGGC CCTCTCCCGTCCGCGGGTGGGGCGC CCGC CGGAGGATA } \\
\text { CCTGAमAAGGAC GTCTC CCGGC CCTCT CCCGTCCGCGGGTGG GGCGC CCGC CGGAGGATA }\end{array}$ \\
\hline $\begin{array}{l}\text { KJ } 677256 \\
\mathrm{KX} 197397\end{array}$ & $\begin{array}{l}\text { CCT GAhA AGGAC GTCTC CCGGC CCTCTCCCGTCCGCGGGTGGGGCGC CCGC CGGAGGATA } \\
\text { CCTGAमAAGGAC GTCTC CCGGC CCTCT CCCGTCCGCGGGTGG GGCGC CCGC CGGAGGATA }\end{array}$ \\
\hline $\mathrm{KX} 197396$ & ССTGAMAAGGAC GTCTC CCGGC CCTCTCCCGTCCGCGGGTGGGGCGC CCGC CGGAGGATA \\
\hline $\begin{array}{l}\text { KX197395 } \\
\text { GU22 } 27866\end{array}$ & $\begin{array}{l}\text { CCT GAAAAGGAC GTCTC CCGGC CCTCTCCCGTCCGCGGGTGGGGCGC CCGC CGGAGGATA } \\
\text { CCTGAमAAGGAC GTCTC CCGGC CCTCTCCCGTCCGCGGGTGG GGCGC CCGC CGGAGGATA }\end{array}$ \\
\hline
\end{tabular}

Fig 2 - Multiple sequence alignment of 5.8S/ITS regions of Colletotrichum truncatum isolates. Polymorphic residues are highlighted. Isolate CoT5 (GenBank KY287676) collected from central India showed polymorphism at two positions, indicating that it is different from all other $C$. truncatum isolates used in this study.

\section{Phylogenetic and evolutionary analysis}

We conducted phylogenetic analysis of 5.8S-ITS sequences from six isolates along with fourteen reference sequences representing Colletotrichum truncatum, C. dematium and Fusarium species. The phylogenetic tree derived from maximum likelihood parsimony analysis consisted of two major clades with $100 \%$ bootstrap support (Fig. 3). The phylogenetic tree clustered all the six isolates with other reference isolates of $C$. truncatum in a single clade irrespective of origin and 
host of the isolate. A second sub-group was formed by C. dematium isolates (GenBank KJ425579 and JX487153); the Fusarium species grouped together in a separate clade. We conducted neutrality tests using ITS sequences of all the six isolated and reference sequences. Strongly negative and significant values suggest recent population expansion or selection. Tajima's $D$ values were negative $(-2.776362, P=0.020109)$ for ITS region in all the isolates and reference sequences.

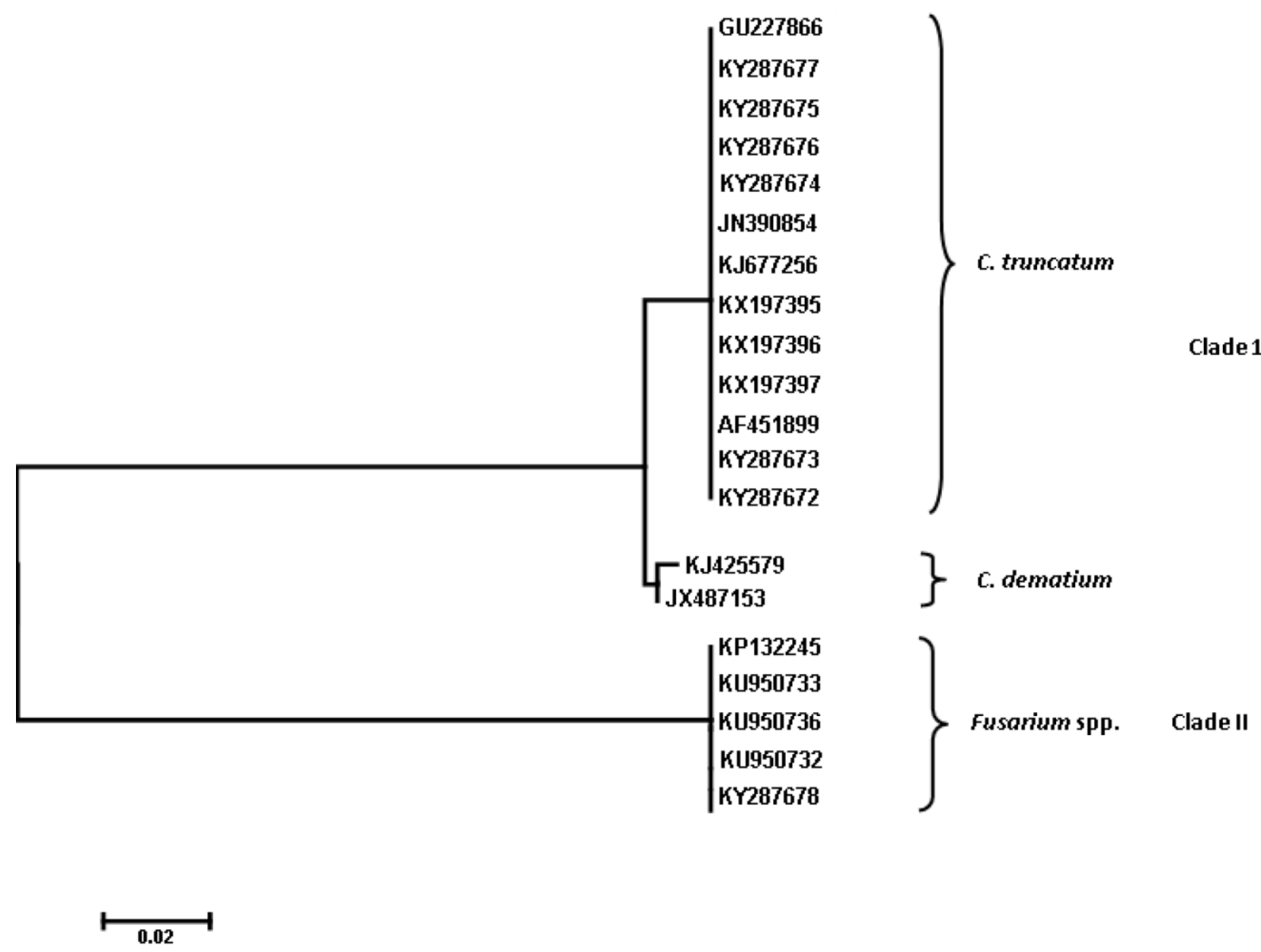

Fig 3 - Phylogenetic analysis of Colletotrichum and Fusarium species based on 5.8S/ITS sequence. All six Colletotrichum truncatum isolates grouped together in clade I.

\section{Discussion}

To our knowledge this is the first report of ITS based genetic variability studies of $C$. truncatum infecting soybean in different geographic region of India. ITS sequences revealed that five $C$. truncatum isolates collected from different geographic regions of India exhibited high similarity with previously reported isolates, but one isolate (CoT5) from Central India was found to be polymorphic at two positions that separated it from all the other $C$. truncatum isolates. Isolate CoT5 shares the nucleotide A at position 74 with another previously reported $C$. truncatum isolate (GenBank GU227880) infecting Capsicum annuum in India (Damm 2009). This indicates that $C$. truncatum infecting Capsicum annuum can also be associated with soybean anthracnose. Two nucleotide changes of isolate CoT5 indicates that this isolate is quite different from all the other $C$. truncatum isolates. Significantly these differences may not necessarily influence the function of the isolates or strains, especially parasitism and pathogenicity on plants. Maximum likelihood tree placed $C$. truncatum together while differentiating it from $C$. dematium and Fusarium sp. Ford et al. (2004) showed $99.8 \%$ identity among ITS-rDNA sequences of $C$. truncatum that were isolated 
from soybean (Glycine max), common bean (Phaseolus vulgaris) and alfalfa (Medicago sativa). This indicated near compete conservation in ITS sequence between isolates from different host species. Based on the 5.8S-ITS information, all the soybean isolates tested in the current study were designated as $C$. truncatum. The differentiation of various isolates of $C$. truncatum based on ITS sequences supports a previous report that $C$. truncatum isolates from different hosts can be identified using ITS based molecular techniques (Ford et al. 2004). Our results will help in understanding the pathogen diversity and in the management of soybean anthracnose.

\section{Acknowledgements}

We thank the Director, ICAR-Indian Institute of Soybean Research, Indore for encouragement and infrastructure facilities.

\section{References}

Bailey JA, Nash C, Morgan, LW, O’Connell RJ, TeBeest DO. 1996 - Molecular taxonomy of Colletotrichum species causing anthracnose on the Malvaceae. Phytopathology 86, 10761083.

Damm U, Woudenberg JHC, Cannon PF, Crous PW. 2009 - Colletotrichum species with curved conidia from herbaceous hosts. Fungal Diversity 39, 45-87.

Diao YZ, Zhang C, Liu F, Wang WZ, Cai L, Liu XL. 2017 - Colletotrichum species causing anthracnose disease of chili in China. Persoonia 38, 20-37.

Ford R, Banniza S, Photita W, Taylor PWJ. 2004 - Morphological and molecular discrimination of Colletotrichum truncatum causing anthracnose on lentil in Canada. Australasian Plant Pathology 33, 559-569.

Jayawardena RS, Hyde KD, Damm U, Cai L et al. 2016 - Notes on currently accepted species of Colletotrichum. Mycosphere 7, 1192-1260.

Johnston PR, Jones D. 1997 - Relationships among Colletotrichum isolates from fruit-rots assessed using rDNA sequences. Mycologia 89, 420-430.

Katoch A, Prabhakar CS, Sharma PN. 2016 - Metageographic population analysis of Colletotrichum truncatum associated with chili fruit rot and other hosts using ITS region nucleotide sequences. Journal of Plant Biochemistry and Biotechnology 25, 64-72.

Khare MN, Chacko S. 1983 - Factors affecting seed infection and transmission of Colletotrichum dematium f. sp. truncata in soybean. Seed Science \& Technology 11, 853-858.

MacLean DJ, Braithwaite KS, Manners JM, Irwing JAG. 1993 - How do we identify and classify fungal pathogens in the era of DNA analysis? Advances in Plant Pathology 10, 207-244.

Manandhar JB, Hartman GL. 1999 - Anthracnose. In: Hartman GL, Sinclair JB, Rupe JC (eds.), Compendium of Soybean Diseases, pp 13-14, 4th edition. St. Paul, APS Press, USA.

Ploper LD, Backman PA. 1992 - Nature and management of fungal diseases affecting soybean stems, pods and seeds. In: Copping LG, Green MB, Rees RT. (eds.), Pest Management in Soybean, pp 174-184. Elsevier Applied Science, London and New York.

Ramdeen S, Rampersad SN. 2012 - Intraspecific differentiation of Colletotrichum gloeosporioides sensu lato based on in-silico multilocus PCR-RFLP fingerprinting. Molecular Biotechnology 53, 170-181.

Sajeesh PK, Rao MSL, Jahagirdar S. 2014 - Molecular detection, transmission and histopathological studies of seed-borne fungal infection of soybean. The Bioscan 9(1), 247251.

Schafer C, Wostmeyer J. 1992 - Random primer dependent PCR differentiates aggressive and nonaggressive isolates of the oilseed rape pathogen Phoma lingam (Leptosphaeria maculans). Journal of Phytopathology 136, 124-136.

Sherriff C, Whelan MJ, Arnold GM, Lafay JF, Brygoo Y, Bailey JA. 1994 - Ribosomal DNA sequence analysis reveals new species groupings in the genus Colletotrichum. Experimental Mycology 18, 121-138. 
Shi A, Kantartzi SK, Mmbaga MT, Chen P, Mrema F, Nnodu E. 2008 - PCR-based markers for detection of Colletotrichum acutatum and C. gloeosporioides in flowering dogwood (Cornus florida). Australasian Plant Pathology 37, 65-68.

Sinclair JB, Backman PA. 1989 - Compendium of Soybean Diseases. ( $3^{\text {rd }}$ edition). American Phytopathological Society, St. Paul, Minnesota, USA, p. 106.

Sreenivasaprasad S, Mills PR, Meehan BM, Brown AE. 1996 - Phylogeny and systematics of 18 Colletotrichum species based on ribosomal DNA spacer sequences. Genome 39, 499-511.

Tajima F. 1989 - Statistical method for testing the neutral mutation hypothesis by DNA polymorphism. Genetics $123,585-595$.

White TJ, Bruns T, Lee S, Taylor JW. 1990 - Amplication and direct sequencing of fungal ribosomal RNA genes for phylogenetics. In: Innis MA, Gelfand DH, Sninsky JJ, White TJ. (eds.), PCR Protocols: A Guide to Methods and Application. Academic Press, San Diego, 315-322. 